\title{
Continuous Subcutaneous Recombinant Parathyroid Hormone (1-34) Infusion in the Management of Childhood Hypoparathyroidism Associated with Malabsorption
}

\author{
Vrinda Saraffa Anya Rothenbuhler ${ }^{b}$ Wolfgang Högler ${ }^{a, c}$ Agnès Linglart ${ }^{b}$

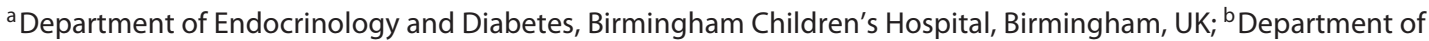 \\ Pediatric Endocrinology, Bicêtre Hospital, Paris, France; ' Institute of Metabolism and Systems Research, University \\ of Birmingham, Birmingham, UK
}

\section{Established Facts}

- Hypoparathyroidism associated with malabsorption can be particularly challenging to manage in children due to limited and often erratic intestinal absorption of calcium and vitamin D analogues.

- Conventional treatment in these children is often associated with symptomatic hypocalcaemia and hypo-/hypercalcaemia-related hospital admissions.

\section{Novel Insights}

- Continuous subcutaneous recombinant parathyroid hormone (1-34) infusion results in the normalization and stabilization of serum calcium and phosphate and therefore is a promising and effective alternative treatment option for children with hypoparathyroidism associated with intestinal malabsorption.

\section{Keywords}

Hypoparathyroidism · Malabsorption · Recombinant parathyroid hormone $\cdot$ Teriparatide $\cdot$ Continuous subcutaneous infusion

\section{Abstract \\ Background/Aims: Hypoparathyroidism associated with malabsorption can be particularly challenging to manage due to limited and erratic intestinal absorption of calcium and vitamin D analogues, resulting in episodes of hypo- or}

(c) 2017 S. Karger AG, Basel

E-Mail karger@karger.com www.karger.com/hrp hypercalcaemia. We evaluated the role of continuous subcutaneous recombinant parathyroid hormone (rhPTH 1-34) infusion (CSPI) in children with hypoparathyroidism associated with intestinal malabsorption resistant to conventional therapy. Method: Four patients (8-13 years of age), with symptomatic hypocalcaemia resistant to conventional therapy, were started on CSPI (follow-up 3-8 years) in two paediatric endocrinology units in Europe. $\boldsymbol{R} \boldsymbol{e}$ -

W. Högler and A. Linglart are joint senior authors.
Dr. Vrinda Saraff

Birmingham Children's Hospital Steelhouse Lane

Birmingham B4 6NH (UK)

E-Mail vrindasaraff@ doctors.org.uk 
sults: Serum calcium normalized within $48 \mathrm{~h}$ of commencing treatment in all 4 patients. An average rhPTH 1-34 dose of $0.4 \mu \mathrm{g} / \mathrm{kg} /$ day resulted in a substantial reduction in symptomatic hypocalcaemia and hypo-/hypercalcaemiarelated hospital admissions. An increased alkaline phosphatase activity was noted in the first 6 months on CSPI, indicating an increase in bone turnover. In 2 patients with elevated urinary calcium excretion before CSPI, this normalized in the first year on treatment. No significant side effects were noticed in the short or long term, with patientreported preference of CSPI over conventional treatment. Conclusion: CSPI is a promising and effective treatment option for managing hypocalcaemia and hyperphosphataemia in children with hypoparathyroidism associated with intestinal malabsorption.

(c) 2017 S. Karger AG, Basel

\section{Introduction}

Hypoparathyroidism is a rare endocrine disorder characterized by low serum calcium with an inappropriately low or normal serum parathyroid hormone (PTH) level [1]. In children, it is commonly associated with either defects in genes involved in parathyroid gland development (TBX1/22q11.2 del, GCMB), function (calciumsensing receptor CaSR, GNA11 and $P T H$ ), or autoimmune polyglandular syndrome type 1 (AIRE) $[2,3]$.

Along with maintaining calcium and phosphate homeostasis through stimulation of osteoclastic bone resorption, PTH plays a vital role in calcium reabsorption and phosphate excretion in the renal tubules. PTH also facilitates conversion of 25-hydroxyvitamin D (25OHD) to the active 1,25-dihydroxyvitamin $\mathrm{D}\left(1,25[\mathrm{OH}]_{2} \mathrm{D}\right)$ which enhances intestinal calcium and phosphate absorption [4].

Unlike other hormone deficiency states, replacing the missing hormone in hypoparathyroidism is not routine practice. Instead, conventional therapy with oral calcium supplements and vitamin D analogues remains the mainstay of treatment [5]. The role of synthetic subcutaneous PTH injections in the treatment of hypoparathyroidism was first reported in adults in $1996[6,7]$ followed by reports in children in 2008 [8]. Since then, short- [9] and long-term studies [10] have demonstrated the efficacy and safety of continuous subcutaneous recombinant PTH 1-34 infusion (CSPI) in the management of hypocalcaemia in children with activating mutations in CaSR and with autoimmune polyendocrinopathy-candidiasisectodermal dystrophy (APECED).
Managing hypocalcaemia with conventional therapy can be particularly challenging in children with hypoparathyroidism associated with intestinal malabsorption, where calcium and active vitamin $\mathrm{D}$ analogue absorption capacity is both limited and highly variable. Here we report the favourable effects of CSPI in 4 children with resistant hypocalcaemia secondary to hypoparathyroidism associated with malabsorption, managed in two tertiary paediatric endocrinology units in Europe, Birmingham Children's Hospital, Birmingham, UK (patient 1 [P1]) and Bicêtre Hospital, Paris, France (patients 2-4 [P2-P4]).

\section{Subjects and Methods}

\section{Case Reports}

Patient 1

A 13-year-old boy, born to consanguineous South Asian parents, was diagnosed with congenital hypoparathyroidism in infancy. He was subsequently diagnosed with sensory neural hearing loss, developmental delay, and cryptogenic liver disease requiring liver transplant at the age of 2 years. He developed persistent diarrhoea with hypoalbuminaemia, lymphopaenia, hypomagnesaemia, and recurrent severe hypocalcaemia by the age of 3 years. Video capsule endoscopy confirmed extensive intestinal lymphangiectasia, not amenable to surgery. Genetic analysis has not identified any significant abnormalities to date. Despite high doses of alfacalcidol (200 ng/kg), oral calcium (300 mg/kg/day), and magnesium supplements $(15 \mathrm{mg} / \mathrm{kg} /$ day) his serum calcium remained between 1.26 and $1.98 \mathrm{mmol} / \mathrm{L}$. High doses of oral calcium supplements led to worsening diarrhoea. Multiple hospital admissions with hypocalcaemic seizures or symptomatic refractory hypocalcaemia requiring intravenous calcium infusions ensued. At the age of 13 years, he was commenced on CSPI delivered via a Medtronic ${ }^{\mathrm{TM}}$ pump and successfully weaned off alfacalcidol, magnesium, and calcium supplements. His serum calcium normalized and stabilized within 2 days of commencing subcutaneous recombinant PTH (rhPTH 1-34). His calcium homeostasis is carefully managed with a combination of $2 \mathrm{~L}$ of medium-chain triglyceride feeds (calcium $35 \mathrm{mg}$ / $\mathrm{kg} /$ day) via gastrostomy in conjunction with rhPTH $1-34$. He also receives regular oesophageal dilatation secondary to oesophageal strictures and recently underwent fundoplication due to severe gastro-oesophageal reflux. He has remained on CSPI for 3 years.

\section{Patient 2}

This 13-year-old boy, born to non-consanguineous Caucasian parents, first presented at the age of 7 years with hypocalcaemic seizures. He was diagnosed with and treated for hypoparathyroidism with conventional therapy. He subsequently developed adrenal insufficiency aged 8.4 years, when a diagnosis of APECED was confirmed with a compound heterozygous mutation in AIRE gene inherited from his parents. He also developed intermittent diarrhoea and hypercalciuria (urinary calcium:creatinine ratio [Ca:Cr, in $\mathrm{mmol} / \mathrm{mmol}] \mathrm{1.3}$ ) on a modest dose of $40 \mathrm{ng} / \mathrm{kg}$ of alfacalcidol. Despite a short trial on thiazide diuretics, hypercalciuria persisted with serum calcium of $1.9 \mathrm{mmol} / \mathrm{L}$. He subsequently developed renal cysts. In view of intestinal malabsorption, poor growth, and a family history of polycystic kidney disease, he was commenced 
Table 1. Clinical and biochemical characteristics of the cohort

\begin{tabular}{|c|c|c|c|c|}
\hline & \multicolumn{4}{|l|}{ Patients } \\
\hline & $\mathrm{P} 1$ & $\mathrm{P} 2$ & P3 & $\mathrm{P} 4$ \\
\hline Sex & $\mathrm{M}$ & M & M & M \\
\hline Age at diagnosis & $8 \mathrm{~m}$ & $7 y$ & $4 \mathrm{y}$ & $11 \mathrm{y}$ \\
\hline Diagnosis & $\begin{array}{l}\text { Congenital } \\
\text { hypoparathyroidism, sensory- } \\
\text { neural deafness, intestinal } \\
\text { lymphangiectasia, cryptogenic } \\
\text { liver disease }\end{array}$ & APECED & APECED & APECED \\
\hline Gene mutation & No abnormality detected & $\begin{array}{l}\text { Compound } \\
\text { heterozygous AIRE } \\
\text { gene mutation (c.415 } \\
\text { C>T exon } 3+ \\
\text { c.967_979del exon 8) }\end{array}$ & $\begin{array}{l}\text { Homozygous AIRE } \\
\text { gene mutation } \\
\text { (c.958del exon 8) }\end{array}$ & $\begin{array}{l}\text { Homozygous } A I R E \\
\text { gene mutation } \\
\text { (c.958del exon 8) }\end{array}$ \\
\hline Coeliac screen & Negative & Negative & Negative & Negative \\
\hline $\begin{array}{l}\text { Faecal calprotectin } \\
\text { activity, } \mu \mathrm{g} / \mathrm{L}^{\mathrm{a}}\end{array}$ & - & 16 & 258 & 62 \\
\hline Faecal elastase, $\mu \mathrm{g} / \mathrm{g}^{\mathrm{b}}$ & $>500$ & 408 & 82 & 40 \\
\hline $\begin{array}{l}\text { Other investigations } \\
\text { for malabsorption }\end{array}$ & $\begin{array}{l}\text { Intestinal biopsy confirmed } \\
\text { extensive lymphangiectasia }\end{array}$ & - & - & - \\
\hline
\end{tabular}

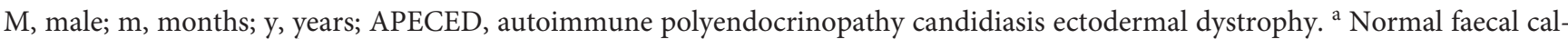
protectin activity $<50 \mu \mathrm{g} / \mathrm{L} .{ }^{\mathrm{b}}$ Normal faecal elastase level $>200 \mu \mathrm{g} / \mathrm{g}$.

on CSPI and pancreatic enzyme replacement (pancrelipase) therapy at the age of 9 years, on which he has remained for 6 years. He is otherwise on a normal diet, his serum calcium stabilized and hypercalciuria resolved subsequently.

\section{Patient 3 and Patient 4}

P3 and P4 are 15- and 19-year-old siblings, born to consanguineous Senegalese parents, with a diagnosis of APECED (homozygous AIRE gene mutation inherited from both parents) and glucose-6-phosphate dehydrogenase deficiency. P3 presented at 4 years of age with hypocalcaemic seizures (serum calcium 1.54 $\mathrm{mmol} / \mathrm{L}$ ). Despite being started on high doses of alfacalcidol (125 $\mathrm{ng} / \mathrm{kg} /$ day) and oral calcium ( $85 \mathrm{mg} / \mathrm{kg} /$ day), he had recurrent hospital admissions with episodes of hypocalcaemia alternating with hypercalcaemia and hypercalciuria. These problems persisted on a brief trial of twice daily subcutaneous injections $(40 \mu \mathrm{g})$ of rhPTH 1-34. Intestinal malabsorption was confirmed due to elevated faecal calprotectin and low faecal elastase levels (Table 1). High doses of oral calcium resulted in worsening diarrhoea, and the decision to commence CSPI was made. P4 presented at the age of 11 years in status epilepticus secondary to hypocalcaemia. Following normalization of serum calcium with intravenous calcium infusions, he was commenced on CSPI, for the purpose of consistency in the management of the two siblings. He subsequently developed diarrhoea, and malabsorption was confirmed by elevated faecal calprotectin and low faecal elastase levels (Table 1). Primary adrenal insufficiency was diagnosed in P3 aged 8 years and $\mathrm{P} 4$ at the age of 12 years. Both were commenced on treatment with hydrocortisone and fludrocortisone as well as on pancrelipase. Both siblings required intermittent intramuscular vitamin D injections, when adequate serum $25 \mathrm{OHD}$ level was not achieved on monthly oral vitamin D supplements (100,000 IU) alone. To our knowledge, $\mathrm{P} 3$ and $\mathrm{P} 4$ were the first reported children to be commenced on CSPI and P3 has remained on it for the longest duration of 8 years [10]. Here we focus on the initiation of their PTH therapy and highlight the challenges in managing resistant hypocalcemia in the context of malabsorption.

P4 deceased at the age of 19 years, after 6.5 years on CSPI treatment, due to acute adrenal insufficiency from septic shock secondary to a dental abscess.

\section{CSPI Dosing and Management}

All patients were commenced on a continuous subcutaneous infusion of rhPTH 1-34 (teriparatide, European Union trade name Forsteo, $20 \mu \mathrm{g} / 80 \mu \mathrm{L}$, Lilly France) delivered via a Medtronic ${ }^{\mathrm{TM}}$ pump. The device was attached to the abdomen or lower back, and parents were trained to fill the pump cartridge with teriparatide and change the cannula and infusion set every $72 \mathrm{~h}$. The pump was programmed to deliver a standard basal rate throughout the day, and carers were trained to either increase basal rate in increments of $10-20 \%$ during illness or self-administer a bolus following discussion with the medical team. P1 was commenced on an 

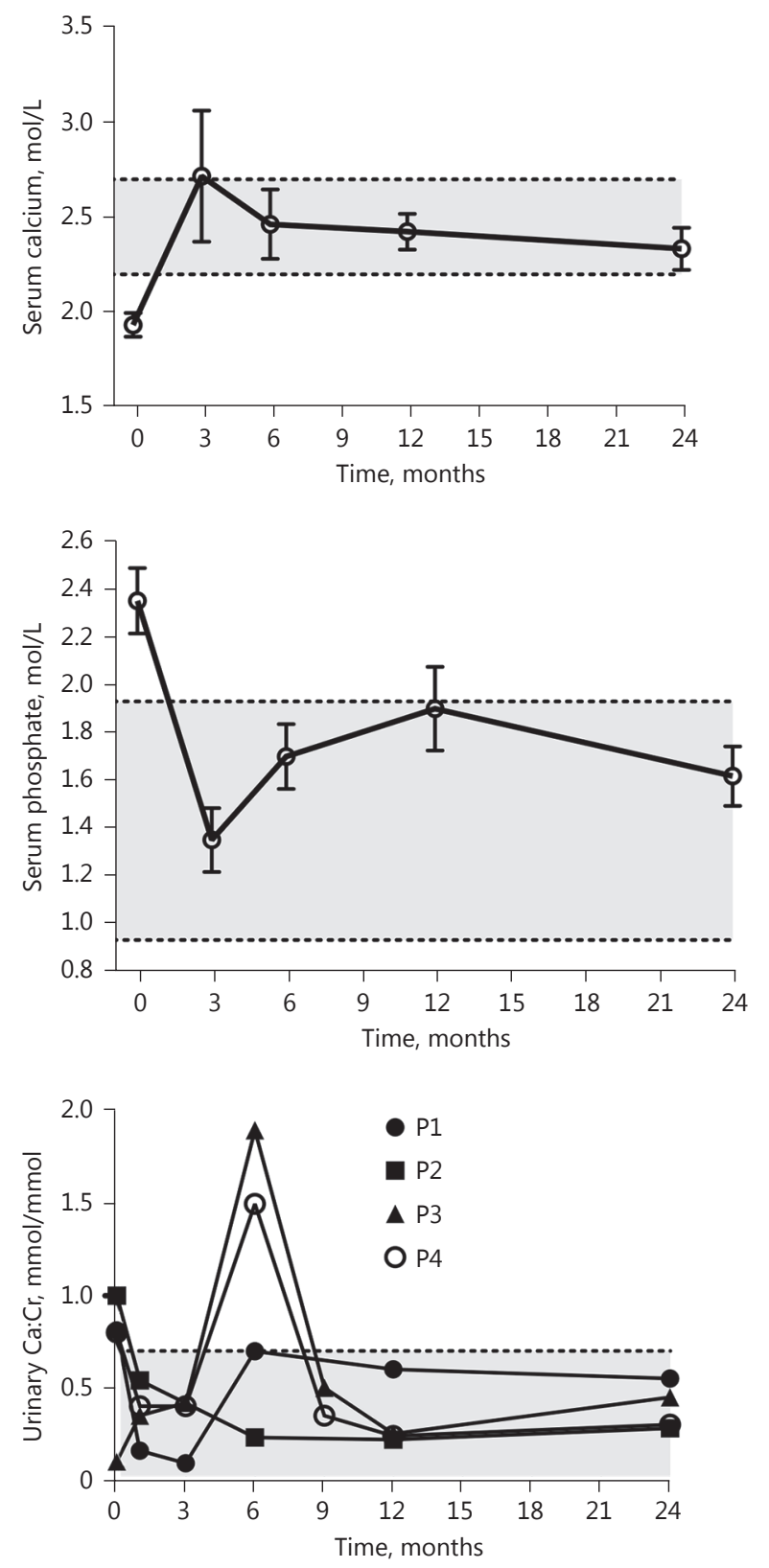

Fig. 1. Normalization and maintenance of serum calcium and phosphate (mean $[S D]$ ) and urinary $\mathrm{Ca}$ :Cr ratio in the first 2 years on CSPI. Shaded area represents normal reference range. High urinary calcium excretion in $\mathrm{P} 3$ and $\mathrm{P} 4,6$ months into treatment, guided rhPTH 1-34 dose reduction. $\mathrm{Ca}: \mathrm{Cr}$, calcium:creatinine ratio; rhPTH 1-34, recombinant PTH 1-34; CSPI, continuous subcutaneous recombinant $\mathrm{PTH}$ 1-34 infusion; P1-P4, patients 1-4.
rhPTH 1-34 dose of $0.16 \mu \mathrm{g} / \mathrm{kg} /$ day, currently requiring a higher maintenance dose of $0.3 \mu \mathrm{g} / \mathrm{kg} /$ day. P2 was on an initial dose of $1 \mu \mathrm{g} / \mathrm{kg} /$ day, which was gradually weaned down to $0.35 \mu \mathrm{g} / \mathrm{kg} / \mathrm{day}$. $\mathrm{P} 3$ and $\mathrm{P} 4$, the very first patients to have commenced on CSPI were started on a higher initial dose of $2.6 \mu \mathrm{g} / \mathrm{kg} /$ day and weaned down to a maintenance dose of $0.5 \mu \mathrm{g} / \mathrm{kg} /$ day in P3 (Table 2) [10].

As this was not a clinical trial, no ethical approval was required. However, as CSPI was commenced in these patients under exceptional circumstances, a multidisciplinary team of experts approved this decision, and individual patient funding requests were obtained from the respective national bodies. Consent was obtained from the parents of all 4 children prior to commencing CSPI treatment, and they were informed of the desired effects, potential side effects, and uncertainties of long-term safety of treatment with CSPI in children.

\section{Results}

Serum calcium normalized in all patients within 36$48 \mathrm{~h}$ of commencing CSPI. All patients were successfully weaned off alfacalcidol and only P3 remains on a reduced dose of oral calcium supplements ( $40 \mathrm{mg} / \mathrm{kg} /$ day). A similar effect was noted with serum phosphate (Fig. 1). P2 and $\mathrm{P} 4$ had elevated $\mathrm{Ca}: \mathrm{Cr}$ at the start of CSPI, which normalized in the first year of treatment (Fig. 1). Episodes of hypercalcaemia and elevated urinary $\mathrm{Ca}: \mathrm{Cr}$ in $\mathrm{P} 3$ and $\mathrm{P} 4$, 3-6 months into treatment guided rhPTH 1-34 dose reduction (Fig. 1).

P1, P3, and P4 had normal renal ultrasound scans with no evidence of nephrocalcinosis before CSPI, and this continues to remain the case on serial renal ultrasounds (1-3 yearly) on treatment. Grade II nephrocalcinosis was detected in P2 in the first year of treatment but did not progress on subsequent ultrasound evaluations. Serum creatinine and estimated GFR remain normal for age in all 4 patients on CSPI.

While $\mathrm{P} 1$ receives gastrostomy feeds, $\mathrm{P} 2$ and $\mathrm{P} 3$ are on a normal diet. Serum calcium throughout treatment remained correlated to $1,25(\mathrm{OH})_{2} \mathrm{D}$ activity in all patients (Fig. 2). The $1,25(\mathrm{OH})_{2} \mathrm{D}$ concentrations were also elevated in all patients during therapy, which in the setting of malabsorption indicates that maximum intestinal calcium absorption capacity is limited. As expected, serum calcium did not correlate with $25 \mathrm{OHD}$ concentrations.

All 4 patients had normal age- and sex-specific alkaline phosphatase (ALP) activity at the start of CSPI. A $60-180 \%$ increase from baseline in ALP activity was noted at 1 month following the start of treatment, which returned to baseline by 6 months on CSPI (Fig. 3).

Lumbar spine bone mineral apparent density $z$ score of $\mathrm{P} 1$ decreased from +3.0 before CSPI to +2.8 and +2.1 , 
Table 2. Dosing, metabolic response, and duration of CSPI

\begin{tabular}{|c|c|c|c|c|}
\hline \multirow[t]{2}{*}{ Patient } & \multicolumn{4}{|c|}{ Patients } \\
\hline & $\mathrm{P} 1$ & $\mathrm{P} 2$ & P3 & $\mathrm{P} 4$ \\
\hline Age at start of CSPI, years & 13 & 9 & 8 & 11 \\
\hline Initiation dose, $\mu \mathrm{g} / \mathrm{kg} /$ day & 0.16 & 1 & 2.6 & 2.6 \\
\hline Maintenance dose at 1 year on CSPI, $\mu \mathrm{g} / \mathrm{kg} /$ day & 0.3 & 0.35 & 0.5 & 0.5 \\
\hline Serum calcium normalized after CSPI initiation, days & 2 & 2 & 2 & 2 \\
\hline Calcium-related hospital admissions, 1 year before CSPI & 8 & 3 & 10 & 1 \\
\hline Calcium-related hospital admissions, 1 year on CSPI & 2 & 1 & 6 & 1 \\
\hline Duration of CSPI therapy to date, years & 3 & 6.5 & 8 & 6.5 \\
\hline
\end{tabular}

CSPI, continuous subcutaneous recombinant PTH 1-34 infusion; P1-P4, patients P1-P4.

at 1 and 2 years on CSPI treatment, respectively. P2-P4 only had lumbar spine bone mineral apparent density measured at 12-18 months on CSPI with $z$ scores of -0.5 , +1.5 , and +1 , respectively. There were no fractures reported in any of the patients on CSPI.

A substantial reduction in hypocalcaemia-related hospital admissions were noted from approximately 5 admissions in the year prior to commencing CSPI to 2 calciumrelated admissions in the first year of treatment (Table 2).

None of the patients had to discontinue CSPI, and they reported a preference of CSPI therapy over conventional treatment due to the perceived improvement in quality of life. P3 has remained on CSPI treatment for 8 years, with no clinically significant treatment-related adverse events being observed.

In our cohort, episodes of hypocalcaemia on CSPI were associated with (1) mechanical obstruction (catheter blockage or kinking), (2) insufficient vitamin D supplementation, (3) systemic illness, which often requires a temporary increase in basal rhPTH 1-34 infusion rates to avoid hypocalcaemia, (4) insufficient oral calcium intake/ gastrostomy milk feeds, and (5) pubertal growth spurt requiring temporary higher rhPTH 1-34 doses to maintain normocalcaemia. In most instances, these episodes occurred secondary to a combination of the above-mentioned factors. No cannula insertion site reactions or infections were recorded in any of the 4 patients.

\section{Discussion}

Symptomatic hypocalcaemia associated with undertreatment is a common occurrence with conventional treatment of hypoparathyroidism. Large doses of oral calcium supplements and alfacalcidol can result in worsen-

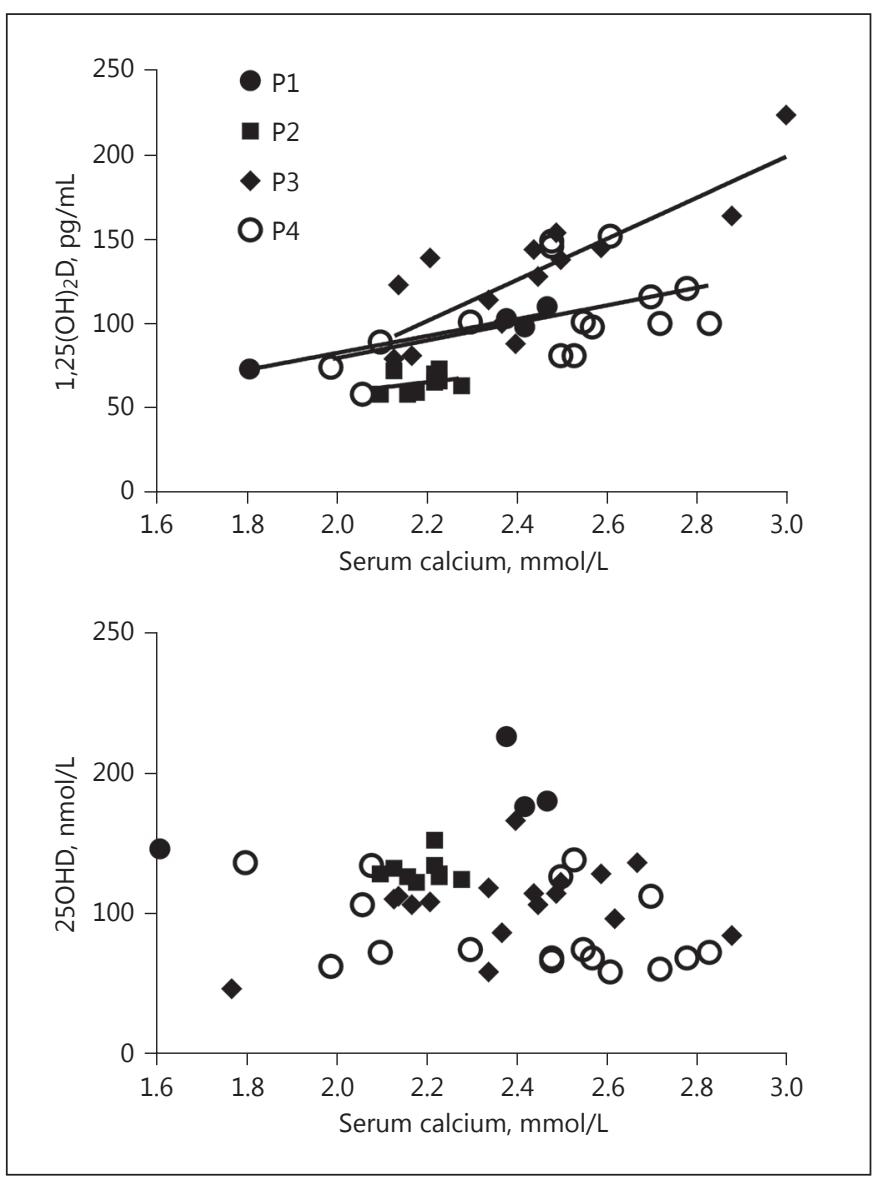

Fig. 2. Serial measurements of serum calcium correlate significantly with rhPTH-driven serum $1,25(\mathrm{OH})_{2} \mathrm{D}$ concentrations (estimated $R^{2}$ value $0.39,95 \%$ confidence interval $0.08-0.68$, and two-sided $p$ value 0.001 using metacor package [18]). Normal range for $1,25(\mathrm{OH})_{2} \mathrm{D}(20-62.5 \mathrm{pg} / \mathrm{mL})$ [19]. A similar correlation with serum $25 \mathrm{OHD}$ concentrations was not evident in children on CSPI. rhPTH 1-34, recombinant PTH 1-34; 1,25(OH $)_{2} \mathrm{D}, 1,25$-dihydroxyvitamin D; 25OHD, 25-hydroxyvitamin D; CSPI, continuous subcutaneous recombinant PTH 1-34 infusion; P1-P4, patients 1-4. 


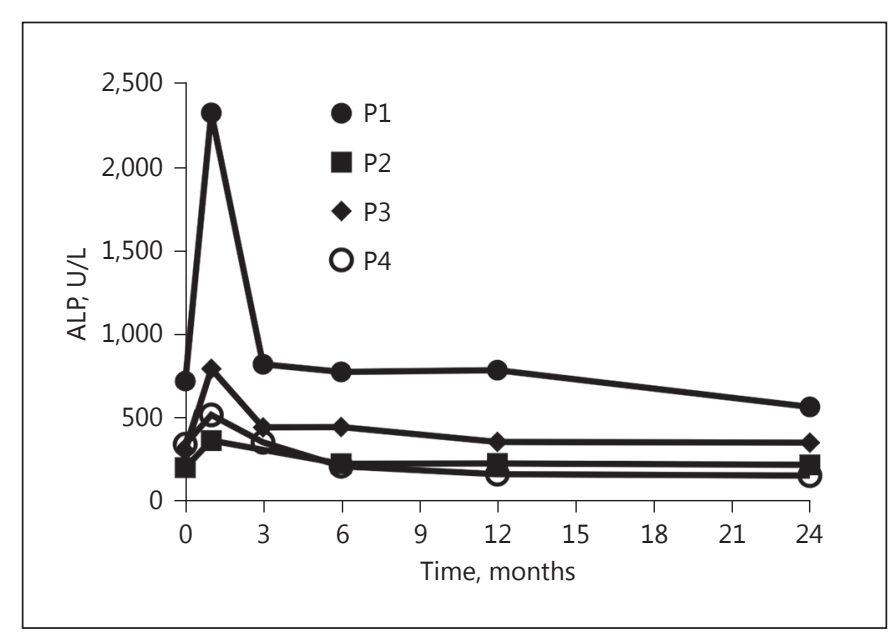

Fig. 3. Effect of CSPI on serum alkaline phosphatase (ALP) activity. The transient rise in ALP activity in the first month demonstrates the restoration of bone turnover followed by normalization of activity by 6 months on treatment. Note that the ALP assay used for P1 results in ALP levels approximately twice the ALP activity of assays used for P2-P4. At the start of therapy, ALP was within the normal range in all patients. CSPI, continuous subcutaneous recombinant PTH 1-34 infusion; P1-P4, patients 1-4.

ing diarrhoea as observed in P1 and P3. In addition, erratic intestinal calcium absorption can lead to fluctuating serum calcium and hypercalciuria resulting in nephrocalcinosis. Here we report our experience demonstrating that this challenging subgroup of patients respond well to CSPI therapy with normalization and stabilization of serum calcium and phosphate resulting in reduced hospital admissions. The daily rhPTH 1-34 maintenance dose varied (Table 2), likely related to the extent of malabsorption. CSPI is also the preferred mode of rhPTH 1-34 delivery in these patients since stabilization is difficult to achieve with twice daily subcutaneous injections. The fixed rhPTH 1-34 doses available as injections are often several times higher than the total daily dose needed during CSPI in these children.

From our experience, it is advisable to maintain $25 \mathrm{OHD}$ levels above $75 \mathrm{nmol} / \mathrm{L}$ in order to provide adequate substrate for PTH-induced conversion of $25 \mathrm{OHD}$ into active calcitriol $\left(1,25[\mathrm{OH}]_{2} \mathrm{D}\right)$. In the setting of malabsorption, it is often challenging to achieve adequate serum $25 \mathrm{OHD}$ by oral supplementation alone. Therefore, regular intramuscular vitamin $\mathrm{D}$ administration should be considered earlier on in the management of these patients as required in $\mathrm{P} 3$ and $\mathrm{P} 4$.

A significant increase in ALP activity was noted within the first month of starting CSPI in our patient cohort, in keeping with the increased bone turnover associated with rhPTH 1-34 treatment in hypoparathyroidism. This however returned to pretreatment levels within 6 months of commencing CSPI. We recognize the lack of consistent 24-h urine calcium assessments in our cohort as well as the challenges in measuring fasting serum calcium due to overnight feed requirement in P1.

All 4 patients reported preference of CSPI over conventional treatment due to the ease of use, fewer episodes of symptomatic hypocalcaemia, and substantial reduction in hospitalization perceived as an improvement in quality of life. Future studies will have to carefully assess quality of life, alongside other functional outcomes and long-term safety monitoring.

Use of conventional treatment remains the mainstay in the treatment of hypoparathyroidism in children, due to the difficulty in dosing with recombinant $\mathrm{PTH}$ and the boxed warning regarding the risk of osteosarcoma noted in rat toxicology studies $[11,12]$ but in no other animal models $[13,14]$. It is essential to inform parents/carers of the possible risks of CSPI treatment. The safety and efficacy of using rhPTH 1-84 as an alternative treatment option needs to be further explored $[15,16]$.

In the absence of other new treatment options on the horizon in children, we propose CSPI as a promising and effective treatment method for children with hypoparathyroidism associated with intestinal malabsorption. However, we recommend careful monitoring of serum calcium daily for the first week, thrice weekly until serum calcium stabilizes in the normal range, later fortnightly, monthly and 3 monthly, or as clinically indicated. To avoid overtreatment, urinary calcium excretion and renal ultrasound should be monitored periodically. Until further evidence becomes available, we recommend bone density scans, total body less head and lumbar spine [17], every 2 years. CSPI should be managed in tertiary rare disease centres with the required expertise. Due to the substantially higher drug costs and uncertainties of longterm adverse events, CSPI is currently restricted to patients unresponsive and/or having serious complications of conventional therapy.

\section{Acknowledgement}

Dr. Saraff was supported by an Early Career Development Award by the European Society of Paediatric Endocrinology. We are thankful to Peter Nightingale, Statistician, Wellcome Trust Clinical Research Facility, Queen Elizabeth Hospital, Birmingham, UK for his statistical input to the manuscript. 


\section{Disclosure Statement}

There is no conflict of interest that could be perceived as prejudicing the impartiality of this study.

\section{Funding Sources}

This study did not receive any specific grant from any funding agency in the public, commercial or not-for-profit sector.

\section{References}

1 Thakker RV: Hypocalcemia: pathogenesis, differential diagnosis, and management; in Favus MJ; American Society for Bone and Mineral Research (eds): Primer on Metabolic Bone Diseases and Disorders of Mineral Metabolism, ed 6. Washington, American Society of Bone and Mineral Research, 2006, pp 213-215.

2 Thakker R: Genetics of endocrine and metabolic disorders: parathyroid. Rev Endocr Metab Disord 2004;5:37-51.

3 Li D, Opas EE, Tuluc F, Metzger DL, Hou C, Hakonarson H, Levine MA: Autosomal dominant hypoparathyroidism caused by germline mutation in GNA11: phenotypic and molecular characterization. J Clin Endocrinol Metab 2014;99:E1774-E1783.

4 Shoback D: Clinical practice. Hypoparathyroidism. N Engl J Med 2008;359:391-403.

5 Chan JC, Young RB, Hartenberg MA, Chinchilli VM: Calcium and phosphate metabolism in children with idiopathic hypoparathyroidism or pseudohypoparathyroidism: effects of 1,25-dihydroxyvitamin D 3. J Pediatr 1985; 106:421-426.

6 Winer KK, Yanovski JA, Cutler GB: Synthetic human parathyroid hormone 1-34 versus calcitriol and calcium in the treatment of hypoparathyroidism: results of a short-term randomized crossover trial. JAMA 1996;276: 631-636.

7 Winer KK, Ko CW, Reynolds JC, Dowdy K, Keil M, Peterson D, Gerber LH, McGarvey C,
Cutler GB Jr: Long-term treatment of hypoparathyroidism: a randomized controlled study comparing parathyroid hormone(1-34) versus calcitriol and calcium. J Clin Endocrinol Metab 2003;88:4214-4220.

8 Winer KK, Sinaii N, Peterson D, Sainz B, Cutler GB: Effects of once versus twice-daily parathyroid hormone 1-34 therapy in children with hypoparathyroidism. J Clin Endocrinol Metab 2008;93:3389-3395.

9 Winer KK, Fulton KA, Albert PS, Cutler GB: Effects of pump versus twice-daily injection delivery of synthetic parathyroid hormone 1-34 in children with severe congenital hypoparathyroidism. J Pediatr 2014;165:556-563.e551.

10 Linglart A, Rothenbuhler A, Gueorgieva I, Lucchini $P$, Silve C, Bougnères P: Long-term results of continuous subcutaneous recombinant PTH (1-34) infusion in children with refractory hypoparathyroidism. J Clin Endocrinol Metab 2011;96:3308-3312.

11 Vahle JL, Long GG, Sandusky G, Westmore M, Ma YL, Sato M: Bone neoplasms in F344 rats given teriparatide (rhPTH[1-34]) are dependent on duration of treatment and dose. Toxicol Pathol 2004;32:426-438.

12 Vahle JL, Sato M, Long GG, Young JK, Francis PC, Engelhardt JA, Westmore MS, Linda Y, Nold JB: Skeletal changes in rats given daily subcutaneous injections of recombinant human parathyroid hormone (1-34) for 2 years and relevance to human safety. Toxicol Pathol 2002;30:312-321.
13 Sietsema WK: Animal models of cortical porosity. Bone 1995; 17:297S-305S.

14 Vahle JL, Zuehlke U, Schmidt A, Westmore M, Chen P, Sato M: Lack of bone neoplasms and persistence of bone efficacy in cynomolgus macaques after long-term treatment with teriparatide (rhPTH[1-34]). J Bone Miner Res 2008;23:2033-2039.

15 Cusano NE, Rubin MR, Bilezikian JP: PTH(184) replacement therapy for the treatment of hypoparathyroidism. Expert Rev Endocrinol Metab 2015;10:5-13.

16 Rubin MR, Dempster DW, Sliney J, Zhou H, Nickolas TL, Stein EM, Dworakowski E, Dellabadia M, Ives R, McMahon DJ, Zhang C, Silverberg SJ, Shane E, Cremers S, Bilezikian JP: PTH(1-84) administration reverses abnormal bone-remodeling dynamics and structure in hypoparathyroidism. J Bone Miner Res 2011;26:2727-2736.

17 Crabtree NJ, Arabi A, Bachrach LK, Fewtrell M, El-Hajj Fuleihan G, Kecskemethy HH, Jaworski M, Gordon CM: Dual-energy X-ray absorptiometry interpretation and reporting in children and adolescents: the revised 2013 ISCD Pediatric Official Positions. J Clin Densitom 2014;17:225-242.

18 Laliberté E: Metacor: Meta-analysis of correlation coefficients. $\mathrm{R}$ package version $1.0-2$, 2011.

19 Lips P: Relative value of $25(\mathrm{OH}) \mathrm{D}$ and 1, 25 $(\mathrm{OH}) 2 \mathrm{D}$ measurements. J Bone Miner Res 2007;22:1668-1671. 